\title{
Comparison of Emergency Medical Services Duration amid Routine Service for COVID-19 Patients
}

\author{
Korakot Apiratwarakul ${ }^{1}$, Takaaki Suzuki ${ }^{2}$, Ismet Celebi ${ }^{3}$, Kamonwon lenghong ${ }^{1 *}$, Thanat Tangpaisarn ${ }^{1}$, Somsak Tiamkao $^{4}$, \\ Vajarabhongsa Bhudhisawasdi ${ }^{1}$
}

${ }^{1}$ Department of Emergency Medicine, Faculty of Medicine, Khon Kaen University, Khon Kaen, Thailand; ${ }^{2}$ Department of Emergency and Critical Care Medicine, University of Tsukuba Hospital, Tsukuba, Japan; ${ }^{3}$ Department of Paramedic, Gazi University, Ankara, Turkey; ${ }^{4}$ Department of Medicine, Faculty of Medicine, Khon Kaen University, Khon Kaen, Thailand

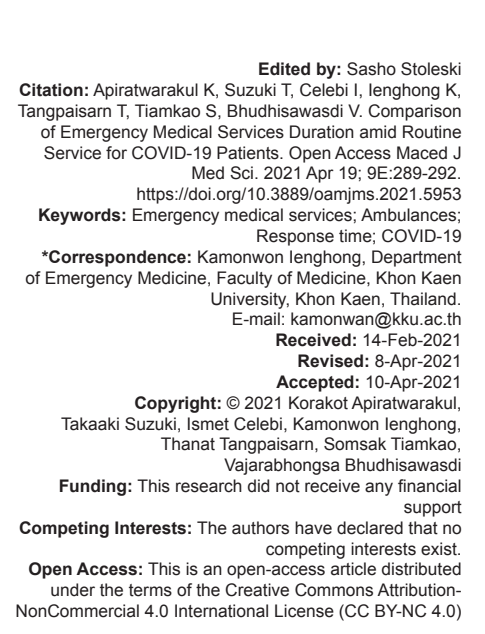

\section{Abstract}

BACKGROUND: Concerning the COVID-19 outbreak in Thailand, the number of patients has been increasing Emergency medical services (EMS) operating duration differs from normal services due to equipment preparation, number of personnel, and on-board ambulance procedures. Notably, there have been no studies examining EMS duration regarding COVID-19 patients.

AIM: The aim of this study was to compare the EMS time for COVID-19 patients and routine services.

METHODS: This cross-sectional study was conducted in a tertiary university hospital in Khon Kaen, Thailand. Information gathering was carried out by employing the Srinagarind Hospital EMS database throughout January 1 , 2020, and February 10, 2021.

RESULTS: A total of 2420 EMS operations were examined, of which five tested positive for COVID-19 (0.21\%) The mean age of the COVID-19 patients was $35.6 \pm 7.2$ years, with the activation interval for COVID-19 and routine services at $64.20 \pm 10.14$ and $1.42 \pm 0.42 \mathrm{~min}$, respectively $(p<0.001)$. The on-scene time for COVID-19 and routine services was $3.20 \pm 0.44$ and $5.20 \pm 2.20 \mathrm{~min}$, respectively.

CONCLUSIONS: EMS operating time amid the activation interval for COVID-19 patients was significantly longer than in the normal group. However, on-scene time for COVID-19 patients was less time than in normal operations.

\section{Introduction}

With regard to the COVID-19 outbreak in Thailand, there has been a growing number of patients from the first outbreak in early 2020 , to the second outbreak in 2021. Accordingly, it was discovered that the outbreak was associated with working in enclosed or congested locations such as food markets or large factories. In addition, a large number of those infected were found through proactive screening. In the case of screening for people at risk of COVID-19, focus on screening took place in communities with nearby sites, epidemic sites, or in the residences of infected individuals. Following a positive coronavirus reading, it is necessary to admit the patient to a hospital or field hospital [1], [2]. Subsequently, there comes a reliance on the operations of the emergency medical services (EMS) to perform their functions. Studies were conducted regarding the COVID-19 infection risk among EMS healthcare workers who were unaware of the risk of infection due to improper wearing of personal protective equipment [2], [3], [4]. Moreover, studies have shown that procedures on-board ambulances are likely to change significantly [4], [5] especially procedures that produce aerosol gases - which may result in the service being altered [6]. Numerous studies have shown that phone calls for EMS have decreased during the COVID-19 epidemic, and the duration of telephone calls has also decreased [7], [8], [9], [10].

In a certain part of Khon Kaen City, which is located in the northeastern part of Thailand, roughly $450 \mathrm{~km}$ from Bangkok is another area where COVID-19 cases have been discovered. Studies have been conducted on the delivery of patients infected with COVID-19. Hence, it was revealed that there was very little published information from the hospital which affects hospital planning [10], [11], [12] in which the EMS operating process differs from normal services, that is, equipment preparation, number of personnel, and on-board ambulance procedures. In China, it was discovered that most patients sent to hospitals had mild symptoms [2], [7]. The most common pre-existing symptom is fever. Studies have shown that during a COVID-19 outbreak, as a result of said outbreak, the 
number of functions provided by the EMS is greatly reduced [8], [11]. Hence, the study of such issues can be used as a guideline for planning future operations.

\section{Methods}

\section{Setting}

Srinagarind Hospital is a university hospital located in Khon Kaen in NE Thailand. Personnel in the EMS consist of emergency medicine physicians (EPs), nurses, advanced emergency medical technicians (AEMTs), emergency medical technicians (EMTs), and emergency medical responders (EMRs), according to competencies required by Thailand's National Institute for Emergency Medicine (NIEM). Services are provided at both the advanced and basic EMS operation levels in which the advanced operation level EPs are involved through direct and indirect medical oversight with telemedicine technology.

\section{Study population and design}

This cross-sectional study was conducted in a tertiary university hospital in Khon Kaen, Thailand. Information was obtained from the EMS database at Srinagarind Hospital throughout the years 2020-2021. Ethical approval was provided by the Khon Kaen University Ethics Committee for Human Research (HE641127). The requirement for informed consent was waived since confidentiality protection had already been guaranteed. Accordingly, participants were not identified by name, but instead by a unique study number.

\section{Sample size and statistical analysis}

Sample size was calculated based on the mean number of Srinagarind Hospital EMS dispatches between 2018 and 2019. To achieve a significance level of 5\% and power of test of 0.8 , we determined that a sample size of 2420 would be required. Statistical analysis was performed using IBM SPSS for Windows version 26.0, Khon Kaen University license (SPSS Inc., Chicago, IL, USA). Categorical data were presented as percentages with continuous data presented employing mean and standard deviation. Univariable analysis was carried out using a two sample t-test for numerical data and Pearson's correlation for data relationship between groups.

\section{Definitions}

Activation interval was defined as the period from receiving the notification of the incident to the ambulance being enroute. Response time was defined as the average times from 1669 center call receipt to arrival on scene. On-scene time was defined as the average time between the responding ambulances arriving on location and when it departs with the patient to the ED. Transfer time was defined as the time between the ambulance's departure from the scene and the destination hospital.

\section{Results}

Between January 1, 2020, and February 10, 2021 , a total of 2,420 EMS operations were examined, of which five tested positive for COVID-19 (0.21\%). The characteristics of the subjects and services are shown in Table 1. The mean age of the COVID-19 patients was 35.6 \pm 7.2 years, with $60.0 \%(n=3)$ being male. Operations concerning COVID-19 related and routine services were most commonly performed during the afternoon shift (4.00 p.m. to 0.00 a.m.), that is, $100.0 \%$ and $37.8 \%$, respectively. The most common level of operations amid COVID-19 services was advanced (100.0\%).

Table 1: Characteristics of the subjects

\begin{tabular}{llll}
\hline Characteristics & $\begin{array}{l}\text { COVID-19 positive } \\
(\mathrm{n}=5), \mathrm{n}(\%)\end{array}$ & $\begin{array}{l}\text { Routine services } \\
(\mathrm{n}=2,415), \mathrm{n}(\%)\end{array}$ & $\mathrm{p}$-value \\
\hline Age (years), mean \pm SD & $35.6 \pm 7.2$ & $45.6 \pm 6.1$ & $0.012^{*}$ \\
$\begin{array}{l}\text { Gender: male } \\
\text { Operation duration }\end{array}$ & $3(60.0)$ & $1498(62.0)$ & 0.084 \\
$\quad$ Morning shift & 0 & $846(35.0)$ & $0.020^{*}$ \\
$\quad$ Afternoon shift & $5(100.0)$ & $912(37.8)$ & \\
$\quad$ Night shift & 0 & $657(27.2)$ & \\
Level of operations & & $814(33.7)$ & 0.082 \\
$\quad \begin{array}{l}\text { Advance team (with EPs) } \\
\text { Basic team (without EPs) }\end{array}$ & $5(100.0)$ & $1,601(66.3)$ & \\
'Statistical significance; SD: Standard deviation; EPs: Emergency Medicine Physicians. &
\end{tabular}

The activation interval for COVID-19 related and routine services was $64.20 \pm 10.14 \mathrm{~min}$ and $1.42 \pm$ 0.42 min, respectively ( $p<0.001$; Table 2 ). The on-scene time for COVID-19 related and routine services was $3.20 \pm 0.44 \mathrm{~min}$ and $5.20 \pm 2.20 \mathrm{~min}$, respectively.

Table 2: EMS operations time

\begin{tabular}{llll}
\hline Operation time & $\begin{array}{l}\text { COVID-19 positive }(\mathrm{min}), \\
\text { mean } \pm \text { SD }\end{array}$ & $\begin{array}{l}\text { Routine services } \\
(\mathrm{min}), \text { mean } \pm \text { SD }\end{array}$ & p-value \\
\hline Activation interval & $64.20 \pm 10.14$ & $1.42 \pm 0.42$ & $<0.001^{*}$ \\
Response time & $8.02 \pm 2.01$ & $8.45 \pm 1.45$ & 0.090 \\
On-scene time & $3.20 \pm 0.44$ & $5.20 \pm 2.20$ & $0.011^{*}$ \\
Transfer time & $5.24 \pm 1.14$ & $6.14 \pm 1.10$ & 0.082 \\
\hline "Statistical significance; min: Minute; SD: Standard deviation. & &
\end{tabular}

\section{Discussion}

The study aimed to compare the time spent employing EMS between COVID-19 positive patients and normal practice. Regarding the age of patients, it was found that the COVID-infected group was significantly younger; which is related to a number of international studies discovering as such amid the second outbreak of COVID-19. Hence, it will spread among working-age groups, students, office workers, and those regularly frequenting enclosed places such as entertainment venues and restaurants [8], [9], [10]. 
As for the procedure duration amid the COVID-19 group, all operations were performed during the afternoon shift as a result of testing incorporating both proactive examination and hospital based examinations with a clear time period. If samples are collected in the morning, laboratory results are issued in the afternoon resulting in EMS delivery after 4 p.m. [11], [12].

At the level of EMS operations for patients with COVID-19, according to the standards of Srinagarind Hospital, doctors are for every case, required to work on-board ambulances to assess symptoms. This includes when emergency procedures are needed, as well as to control and direct the actions of team members to prevent infection from patients [13], [14], [15], [16].

In terms of operating time by EMS, the activation interval of those infected with COVID-19 is significantly longer than normal. This is because in the case of delivery of a COVID-19 patient, EMS personnel have to put on personal protective equipment which takes time. This also applies to the preparation of specific equipment such as a Patient Isolation Transport Unit (PITU) to prevent the spread of infection. In addition, the coordination between the patient receiving locations must provide a dedicated channel which is not mixed with other patients. For this reason, preparation time during the activation interval is longer than usual.

Furthermore, on-scene time concerning COVID-19 patients requires less time than normal operations, due to the fact that most cases are mild cases. Such patients are able to walk by themselves and there is no urgent procedure needing to be done - thus reducing time. There was one case of COVID 19 with moderate symptoms. Those exhibiting difficulty breathing with hypoxia were transported utilizing a PITU. This study was limited in that information was collected from only one EMS center. Moreover, the design of study was retrospective which may have resulted in incomplete data gathering [13], [14], [15], [16], [17].

\section{Conclusion}

EMS operating time and activation interval regarding COVID-19 patients were significantly longer than in the normal group. Conversely, on-scene duration among COVID-19 patients was less than in normal operations.

\section{Acknowledgments}

The authors would like to thank Jiranan Thedmee, Thanyaporn Simsen, and Siwaporn
Kwansanei for their data analysis and statistical review. We also wish to thank Mr. Ross Lacey for acting as an English consultant.

\section{References}

1. Heinzerling A, Stuckey MJ, Scheuer T, Xu K, Perkins KM, Resseger $\mathrm{H}$, et al. Transmission of COVID-19 to health care personnel during exposures to a hospitalized patient Solano County, California, February 2020. MMWR Morb Mortal Wkly Rep. 2020;69(15):472-6. https://doi.org/10.15585/mmwr. $\mathrm{mm} 6915 \mathrm{e} 5$

PMid:32298249

2. Tian $\mathrm{S}$, Hu N, Lou J, Chen $\mathrm{K}$, Kang $\mathrm{X}$, Xiang Z, et al Characteristics of COVID-19 infection in Beijing. J Infect. 2020;80(4):401-6. https://doi.org/10.1016/j.jinf.2020.02.018 PMid:32112886

3. Fernandez AR, Crowe RP, Bourn S, Matt SE, Brown AL, Hawthorn AB, et al. COVID-19 preliminary case series: Characteristics of EMS encounters with linked hospital diagnoses. Prehosp Emerg Care. 2021;25(1):16-27. https://doi. org/10.1080/10903127.2020.1792016

PMid:32677858

4. Satty T, Ramgopal S, Elmer J, Mosesso VN, Martin-Gill C. EMS responses and non-transports during the COVID-19 pandemic. Am J Emerg Med. 2020;42:1-8. https://doi.org/10.1016/j. ajem.2020.12.078

PMid:33429185

5. Nolan JP, Monsieurs KG, Bossaert L, Böttiger BW, Greif R, Lott $\mathrm{C}$, et al. European resuscitation council COVID-19 guidelines executive summary. Resuscitation. 2020;153:45-55. https://doi.org/10.1016/j.resuscitation.2020.06.001 PMid:32525022

6. Cabañas JG, Williams JG, Gallagher JM, Brice JH. COVID-19 pandemic: The role of EMS physicians in a community response effort. Prehosp Emerg Care. 2021;25(1):8-15. https://doi.org/10 $.1080 / 10903127.2020 .1838676$

PMid:33074060

7. Niu S, Tian S, Lou J, Kang X, Zhang L, Lian H, et al. Clinical characteristics of older patients infected with COVID-19: A descriptive study. Arch Gerontol Geriatr. 2020;89:104058. https://doi.org/10.1016/j.archger.2020.104058

PMid:32339960

8. Maudet L, Sarasin F, Dami F, Carron PN, Pasquier M Emergency medical services: COVID-19 crisis. Rev Med Suisse. 2020;16(N 691-2):810-4

PMid:32348041

9. Penverne $\mathrm{Y}$, Jenvrin J, Montassier E. EMS dispatch center activity during the COVID-19 containment. Am J Emerg Med. 2020;2020:30678-1. https://doi.org/10.1016/j.ajem.2020.07.083 PMid:32826107

10. Yang BY, Barnard LM, Emert JM, Drucker C, Schwarcz L, Counts CR, et al. Clinical characteristics of patients with coronavirus disease 2019 (COVID-19) receiving emergency medical services in King County, Washington. JAMA Netw Open. 2020;3(7):e2014549. https://doi.org/10.1001/ jamanetworkopen.2020.14549 PMid:32639570

11. Saberian $\mathrm{P}$, Conovaloff $\mathrm{JL}$, Vahidi $\mathrm{E}$, Hasani-Sharamin $\mathrm{P}$ Kolivand PH. How the COVID-19 epidemic affected 
prehospital emergency medical services in Tehran, Iran. West J Emerg Med. 2020;21(6):110-6. https://doi.org/10.5811/ westjem.2020.8.48679

PMid:33052824

12. Ventura C, Gibson C, Collier GD. Emergency Medical Services resource capacity and competency amid COVID-19 in the United States: preliminary findings from a national survey. Heliyon. 2020;6(5):e03900. https://doi.org/10.1016/j.heliyon.2020 e03900

PMid:32368629

13. lenghong K, Kulsutcharit K, Apiratwarakul K, Gaysonsiri D, Mitsungnern T, Bhudhisawasdi V. Characteristics and mortality in high-, intermediate-, and low-risk acute pulmonary embolism patients in the emergency department. J Med Assoc Tha 2020;103(Suppl 6):42-6.

14. lenghong $\mathrm{K}$, Ussahgij $\mathrm{W}$, Kanthachat $\mathrm{K}$, Apiratwarakul $\mathrm{K}$,
Phungoen $\mathrm{P}$, Bhudhisawasdi V. Factors associated with severe intracranial pathology in acute non-traumatic headache patients in the emergency department. J Med Assoc Thai 2020;103(Suppl 6):47-50.

15. Apiratwarakul $\mathrm{K}$, Mitsungnern $\mathrm{T}$, Thatphet $\mathrm{P}$, lenghong $\mathrm{K}$, Ruttanaseeha W, Bhudhisawasdi V. Management of anaphylactic patients by emergency medical services. J Med Assoc Thai 2020;103(Suppl 6):11-4.

16. Apiratwarakul $\mathrm{K}$, Pumiyoch $\mathrm{P}$, lenghong $\mathrm{K}$, Phungoen $\mathrm{P}$, Gaysonsiri D, Bhudhisawasdi V. Endotracheal intubation on a stationary vs. moving ambulance. J Med Assoc Thai 2020;103(Suppl 6):18-21.

17. Apiratwarakul $K$, lenghong $K$, Gaysonsiri $D$, Buranasakda $M$, Bhudhisawasdi V, Tiamkao S. Role of motorcycle-based ambulance (motorlance) in major sporting events. J Med Assoc Thai 2020;103(Suppl 6):15-7. 